\title{
Realizacija m-učenja primjenom BYOD modela u osnovnoj školi
}

\author{
Tamara Ređep \\ I. osnovna škola Varaždin \\ Kralja P. Krešimira IV. 10 \\ 42000 Varaždin \\ tamara.redep@skole.hr
}

\author{
Tomislav Leček \\ III. osnovna škola Varaždin \\ Trg Ivana Perkovca 35 \\ 42000 Varaždin \\ tomislav.lecek@os-treca-vz.skole.hr
}

\author{
Tea Pavičić Zajec \\ I. osnovna škola Varaždin \\ Kralja P. Krešimira IV. 10 \\ 42000 Varaždin \\ tea232pavi@hotmail.com
}

\section{Sažetak}

Mobilno učenje ili m-učenje omogućuje moderan način podrške procesima učenja putem mobilnih uređaja. Jedan od načina realizacije $m$-učenja je primjena BYOD modela na nastavi, prema kojem učitelji uglavnom iskazuju negativan stav smatrajući da korištenje mobitela u obrazovanju bitno ne pridonosi kvaliteti nastavnog procesa. Istraživanje za potrebe ovog rada provedeno je u ožujku školske godine 2018./2019., na uzorku od 401 učenika predmetne nastave I. i III. OŠ Varaždin. Cilj je bio ispitati stavove $i$ preferencije učenika osnovnih škola o korištenju mobitela u sklopu nastavnog procesa te postoji li razlika u percepciji učenika osnovnih i srednjih škola o dopuštenju da donose vlastite uređaje za aktivnosti povezane sa školom. Rezultati istraživanja pokazuju da čak 65,69\% učenika tvrdi da im je nastava zanimljivija kada smiju koristiti svoj mobilni uređaj, a 70,38\% ispitanika želi da više učitelja primjenjuje BYOD model na nastavi. Također, rezultati pokazuju i da se u svojim razmišljanjima o dopuštenju da donose vlastite uređaje za aktivnosti povezane sa školom ne razlikuju značajno od učenika srednjih škola.

Ključne riječi: mobilni telefoni; BYOD; m-učenje; bežična mreža; učenici; učitelji; nastava.

\section{Uvod}

Ubrzan razvoj IKT ${ }^{1}$ - a i evolucija mobilnih uređaja mijenjaju način i učenja i poučavanja (Vanwelsenaers, 2012).

Učenici preko svojih bežičnih osobnih uređaja $s$ mogućom stalnom internet vezom imaju na dohvat ruke neograničeni pristup digitalnom sadržaju, bazama podataka i interesnim zajednicama. Djelotvornim iskorištavanjem takvih resursa, škole mogu produbljivati učenje, a također mogu razviti digitalnu pismenost učenika koja će ih pripremiti za visoko tehnološki svijet u kojem će živjeti, učiti i raditi (Alberta Education, 2012).

${ }^{1}$ Informacijska i komunikacijska tehnologija 
No, iako rezultati raznih istraživanja pokazuju da upotreba tehnologije, posebno mobitela i tableta, pridonosi motivaciji učenika, te potiče suradnju i interakciju između učenika, ali i učitelja (Krmek, 2014), postavlja se pitanje zašto onda, ipak, pojedine škole uvode zabranu mobilnih uređaja.

\section{BYOD ${ }^{2}$ model u obrazovanju}

Mobilno učenje ili m-učenje omogućava moderan način podrške procesima učenja putem mobilnih uređaja (Maravić, 2013). Jedan od načina realizacije m-učenja je uvođenje BYOD modela, $u$ kojem učenici $u$ školu na nastavu donose svoj osobni mobilni uređaj s kojim pristupaju bežičnoj mreži (internetu) u svrhu učenja (Stavert, 2014). Najčešće su to pametni mobilni telefoni ili tablet računala.

U članku "Pametno s pametnim telefonima" (Tadić, 2017) o provođenju BYOD programa u Javnom školskom sustavu okruga Wake u Sjevernoj Karolini, ravnatelj i učitelji zaključuju kako sada, čak i ne shvaćajući to, učenici smatraju svoje uređaje manje igračkama, a više obrazovnim alatom. Učitelji ne moraju više paziti na učenike koji šalju poruke iz hodnika ili se skrivajući igraju svojim telefonima. Stvar je sada kultivirana jer se telefoni koriste za obrazovne svrhe što pomaže oblikovanju kulture u čitavoj školi.

Kako Hrvatska nema propisanih pravila o upotrebi mobitela, već to ovisi isključivo o stavovima ravnatelja, a što škole tada definiraju u svojem kućnom redu, tako su i situacije u školama različite. U nekim školama učenici smiju koristiti mobitele za vrijeme školskih odmora, ali ne i na nastavi, dok su neke osnovne škole po uzoru na Francusku, uporabu mobitela u potpunosti zabranile. Učenici mobitel mogu ponijeti u školu, no do posljednjeg zvona on mora biti ugašen $i$ spremljen u torbi, čak i za vrijeme odmora. U tim školama tvrde da su se učenici priviknuli na nova pravila, te da imaju samo pozitivne komentare jer se osjećaju puno bolje i sigurnije obzirom da više

${ }^{2}$ BYOD (engl). Bring your own device -,Donesite svoj uređaj“ ne strahuju da će ih netko tajno fotografirati ili snimiti (Jazbec, 2018).

U Varaždinskoj županiji učenici nisu željeli prihvatiti moguće ograničenje uporabe mobitela. Naime, tijekom prosinca 2018. godine Varaždinska županija je od ravnatelja osnovnih i srednjih škola zatražila da pravilnicima o kućnom redu reguliraju korištenje mobitela. Prema naputku koji je poslan školama, učenici smiju nositi mobitel u školu, no ne smiju ga uključivati bez nadzora nastavnika ili ravnatelja, osim u hitnim slučajevima. Tijekom pisanih provjera znanja, mobitele moraju odložiti u posebnu kutiju. Najstroža mjera je privremeno oduzimanje mobitela, koji bi učenicima bio vraćen tek u prisutnosti roditelja ili skrbnika. Vijeće učenika Varaždinske županije s takvim se ograničenjima nije složilo te je uspjelo izboriti korištenje mobitela i tijekom odmora. Smatraju da do zloupotrebe može doći jedino kod profesora koji ne predaju dovoljno dobro i edukativno te da bi mobilni uređaji morali biti uvedeni u redovnu nastavu primjenjujući ih za korištenje edukativnih aplikacija (Gelenčir, 2018).

Da se učitelji većinom ne slažu s takvim stavom učenika pokazuju i rezultati dvaju istraživanja. U istraživanju Krmeka M. (Krmek, 2014) provedenog u lipnju 2017. godine za potrebe diplomskog rada "Mobilne tehnologije $u$ nastavi", ispitani su stavovi učitelja o korištenju mobilnih tehnologija u nastavnom procesu, te razlike $u$ stavovima $s$ obzirom na mjesto rada $i$ osobne karakteristike ispitanika. lako gotovo svi učitelji posjeduju pametne telefone i oko $60 \%$ njih je koristilo ili koristi mobilne tehnologije u nastavi, dobiveni rezultati spomenutog istraživanja pokazuju da stavovi tih učitelja i dalje nisu pretežito pozitivni. No, ipak može se zaključiti da bi veći broj učitelja primjenjivao mobilne tehnologije u nastavnom procesu kada bi za to postojala mogućnost dodatne edukacije. $U$ drugom istraživanju "Mobiteli u nastavi: stavovi $i$ iskustva učitelja" provedenom u veljači 2014. godine, Skupnjak D. (Skupnjak, 2014) ispituje percepciju učitelja o opravdanosti korištenja mobitela u nastavi te dosadašnja učiteljska iskustva korištenja učeničkih mobitela u nastavi. Rezultati pokazuju da učitelji, usprkos relativno 
dobroj samoprocjeni osposobljenosti za korištenje mobitela, uglavnom iskazuju negativan stav prema korištenju mobitela u obrazovanju, smatrajući da on bitno ne pridonosi kvaliteti nastavnog procesa.

\section{Metodologija istraživanja}

Cilj istraživanja opisanog u ovom radu bio je ispitati stavove i preferencije učenika osnovnih škola o korištenju mobitela u sklopu nastavnog procesa, te postoji li razlika u percepciji učenika osnovnih i srednjih škola o dopuštenju da donose vlastite uređaje za aktivnosti povezane sa školom. Za usporedbu odgovora učenika srednje škole koristili smo podatke dobivene $u$ online istraživanju provedenom u siječnju 2018. godine kojem je pristupilo 210 učenika Tehničke škole u Požegi. Rezultate tog istraživanja autorica Mirković M. objavila je u radu „BYOD u obrazovanju“, koji je 2018. godine predstavila na 41. međunarodnom skupu MIPRO u kategoriji savjetovanje Računala u obrazovanju.
$\mathrm{Na}$ temelju analize dobivenih rezultata prethodno provedenih istraživanja, u radu se polazi od dvije hipoteze:

H1: Učenici neovisno o spolu i dobi smatraju da bi im nastava bila zanimljivija uz korištenje osobnih mobilnih uređaja $i$ željeli bi da više učitelja primjenjuje BYOD model.

H2: Ne postoji značajna razlika u percepciji učenika osnovnih i srednjih škola o dopuštenju da donose vlastite uređaje za aktivnosti povezane sa školom.

Istraživanje je provedeno u ožujku školske godine 2018./2019. u I. i III. osnovnoj školi Varaždin jer ove škole osim stalne žične mreže posjeduje i bežičnu mrežnu infrastrukturu. Prednost korištenje ovih mreža je filtriranje prometa tako što se mrežne stranice kategoriziraju obzirom na prikazani sadržaj.

Uzorak u ovom istraživanju obuhvatio je 401 učenika predmetne nastave I. i III. osnovne škole Varaždin, s podjednakim udjelom ispitanika obzirom na spol i razred (Tablica 1).

\begin{tabular}{|c|c|c|c|}
\hline \multirow{2}{*}{ Razred } & \multicolumn{2}{|c|}{ Spol } & \multirow{2}{*}{ Ukupno } \\
\cline { 2 - 3 } & $\mathbf{M}$ & $\check{\mathbf{Z}}$ & \\
\hline V. & $16,71 \%$ & $12,72 \%$ & $\mathbf{2 9 , 4 3 \%}$ \\
\hline VI. & $14,71 \%$ & $11,22 \%$ & $\mathbf{2 5 , 9 4 \%}$ \\
\hline VII. & $11,72 \%$ & $12,47 \%$ & $\mathbf{2 4 , 1 9 \%}$ \\
\hline VIII. & $11,22 \%$ & $9,23 \%$ & $\mathbf{2 0 , 4 5 \%}$ \\
\hline Ukupno & $\mathbf{5 4 , 3 6 \%}$ & $\mathbf{4 5 , 6 4 \%}$ & $\mathbf{1 0 0 \%}$ \\
\hline
\end{tabular}

Tablica 1: Opis uzorka - učenici

Za potrebe istraživanja kreiran je online anketni upitnik $u$ alatu Google obrasci koji se sastojao od pitanja zatvorenog tipa s unaprijed ponuđenim odgovorima. Zbog prethodno definiranog cilja usporedbe $\mathrm{i}$ ispitivanja razlike $u$ odgovorima učenika osnovne i srednje škole, odgovore o tome zašto bi koristili mobitel na nastavi te na koji će način donošenje njihovog vlastitog uređaja u školu utjecati na učenje preuzeta su iz rada "BYOD u obrazovanju“ autorice Mirković M. (Mirković, 2018).

Na pitanje nose li mobilni uređaj (mobitel) u školu, 69,33\% učenika odgovorilo je potvrdno, $15,71 \%$ učenika mobilni uređaj nosi ponekad, 
$14,21 \%$ učenika u školu uopće ne nosi mobilni uređaj, a tek samo $0,75 \%$ učenika ne posjeduje mobilni telefon.

$U$ daljnjem ispitivanju sudjelovali su samo oni učenici koji su se izjasnili da mobilni uređaj u školu nose stalno ili ponekad ( $N=341$ ). Od njih čak $65,69 \%$ smatra da im je nastava zanimljivija kada smiju koristiti svoj mobilni uređaj, $18,48 \%$ učenika smatra da je to samo ponekad, $1,46 \%$ se uopće ne slaže s tom tvrdnjom, a $14,37 \%$ učenika ne smije koristiti mobitel za potrebe nastave. Da više učitelja primjenjuje BYOD model na nastavi želi $70,38 \%$ učenika, $4,99 \%$ to ne želi, dok je $24,63 \%$ učenika to svejedno.

Detaljnijom analizom podataka (Slika 1) utvrđeno je da učenici neovisno o spolu i dobi smatraju da bi im nastava bila zanimljivija uz korištenje osobnih mobilnih uređaja te da bi željeli da više učitelja primjenjuje BYOD model. Ovi podaci u potpunosti potvrđuju prvu hipotezu.

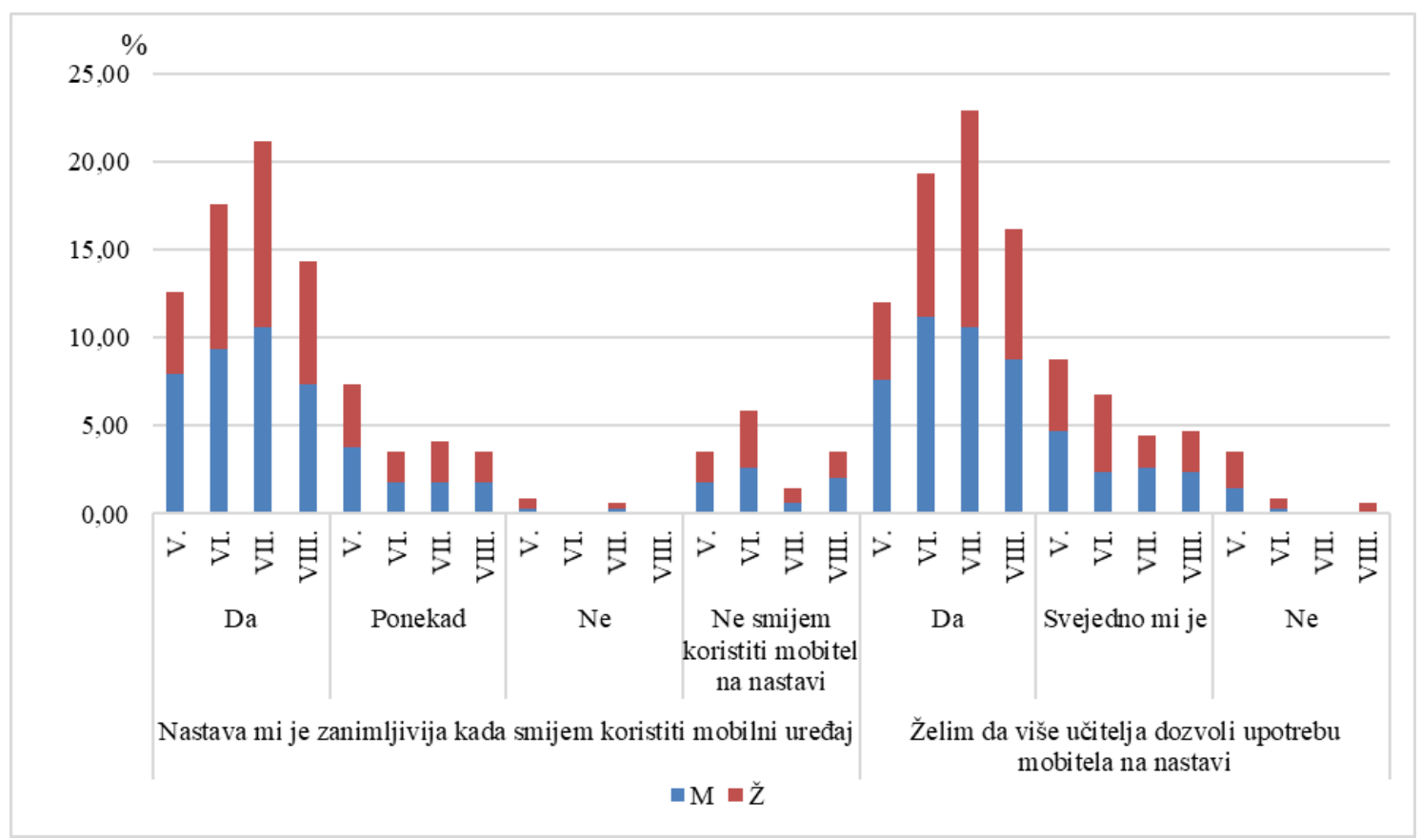

Slika 1. Stavovi učenika o korištenju mobitela na nastavi obzirom na spol i dob ( $N=341)$

Odgovarajući na pitanje zašto bi koristili mobitel u osnovnoj školi najveći broj učenika $(62,5 \%)$ izabrao je opciju da bi mobitel koristili pri istraživanju za projekt, a najmanje za komunikaciju s nastavnikom (14,7\%). Kod tvrdnje „istraživanje za projekt“ pretpostavka je da se misli na školske projektne zadatke koji zahtijevaju da učenici potraže dodatne informacije na internetu. Kao najveći utjecaj donošenja vlastitog uređaja na učenje, učenici su odabrali mogućnost bržeg pristupanja informacijama za istraživanje putem mobilnih uređaja $(72,4 \%)$, a najmanje će mobiteli utjecati na njihovu angažiranost pri učenju $(32,8 \%)$.

Uspoređujući dobivene rezultate $s$ rezultatima istraživanja Mirković M. (Mirković, 2018) (Slika 2. i Slika 3.) došli smo do zaključka da postoje vrlo male razlike u percepciji učenika osnovnih $\mathrm{i}$ srednjih škola o dopuštenju da donose vlastite uređaje za aktivnosti povezane sa školom. No, iako bi i učenici srednje škole vlastiti uređaj upotrebljavali najmanje za komunikaciju $\mathrm{s}$ nastavnikom $(28,7 \%)$ i dalje bi ga koristili najviše za komunikaciju s prijateljima (88,6\%). Kao i učenici osnovne škole, smatraju da će donošenje 
vlastitog uređaja u školu najviše utjecati na njihovo učenje zbog bržeg pristupa informacijama za istraživanje $(77,7 \%)$, a najmanji će utjecaj imati mogućnost slanja radova nastavnicima digitalno (50,3\%). Obzirom na dobivene rezultate druga hipoteza je samo djelomično potvrđena.

\section{Zašto bi koristio mobitel u školi}

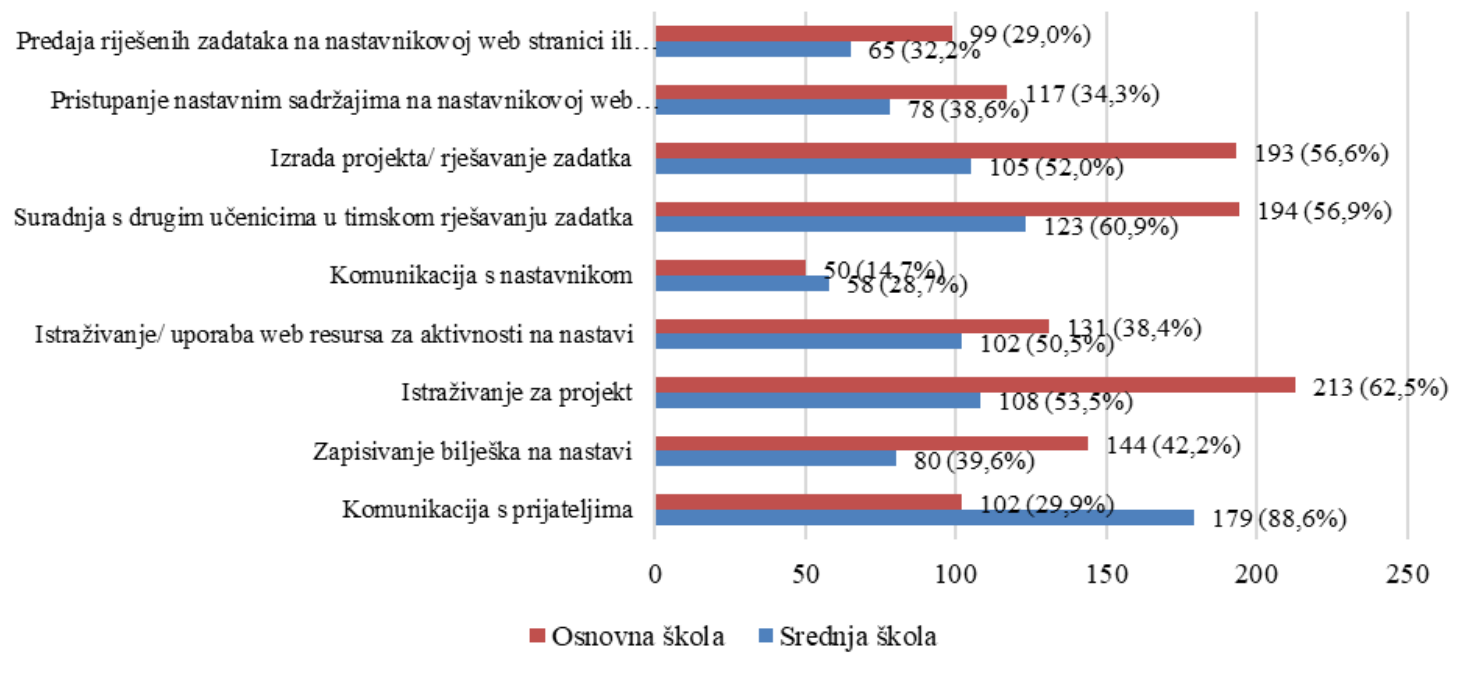

Slika 2. Odgovori učenika zašto bi koristili mobitel na nastavi $(\mathrm{N}=341)$

\section{Na koji način će donošenje vlastitog uređaja u školu utjecati na tvoje učenje}

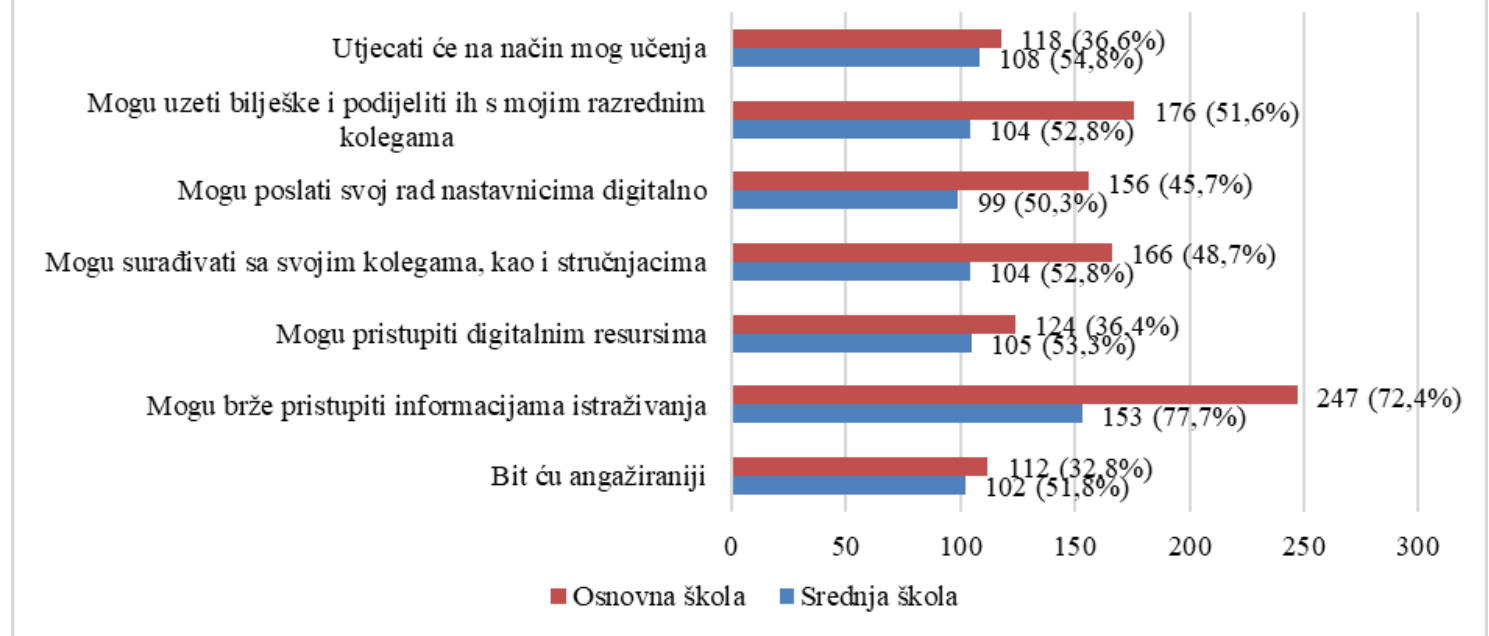

Slika 3. Odgovori učenika na koji će način donošenje njihovog vlastitog uređaja u školu utjecati na učenje ( $N=341)$ 


\section{Rezultati i diskusija}

Na temelju prednosti i nedostataka o primjeni BYOD-a opisanih u literaturi (Wainwright, 2012), rezultata dobivenih $u$ prethodno provedenim istraživanjima te onih dobivenih $u$ ovom istraživanju, napravljena je SWOT analiza kako bi se školama olakšala odluka o donošenju pravila za realizaciju m-učenja primjenom BYOD modela.

\begin{tabular}{|c|c|}
\hline (unutarnje) SNAGE & (unutarnje) SLABOSTI \\
\hline 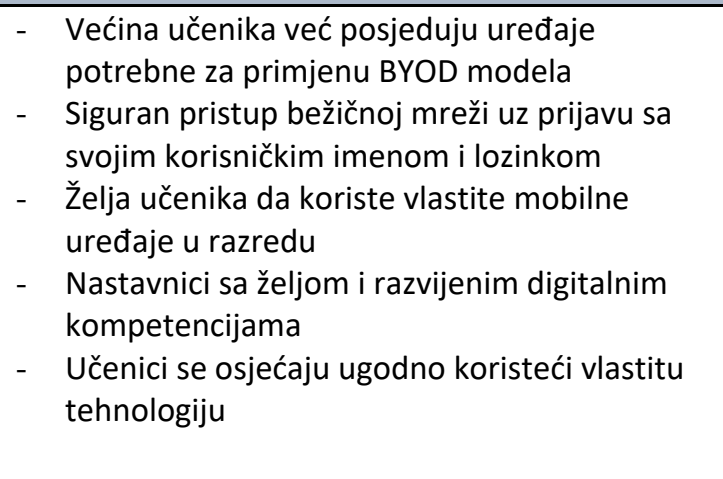 & $\begin{array}{ll}\text { - } & \text { Tehničke poteškoće vezane uz pristup } \\
\text { bežičnoj mreži } \\
\text { - } & \text { Pojedini nastavnici ne žele unaprijediti svoju } \\
\text { nastavu uz primjenu IKT-a } \\
\text { - } \quad \text { Neujednačeno razvijena digitalna } \\
\text { kompetencija nastavnika } \\
\text { - } \quad \text { Mogućnost krađe ili gubitka uređaja } \\
\text { - } & \text { Nedovoljna tehnička podrška na nastavi i } \\
& \text { izvan nje } \\
\text { - } & \text { Svi učenici si možda neće moći priuštiti } \\
& \text { mobilni uređaj }\end{array}$ \\
\hline (vanjske) MOGUĆNOSTI & (vanjske) PRIJETNJE \\
\hline $\begin{array}{ll}\text { - } & \text { Sveprisutnost bežičnih internetskih uređaja } \\
\text { - } & \text { Mobilni uređaji su lako prenosivi } \\
\text { - } & \text { Neograničen pristup informacijama i } \\
\text { resursima } & \text { Dostupnost pohrane i aplikacija temeljenih na } \\
\text { - } & \text { oblaku } \\
\text { - } & \text { Uz digitalne udžbenike postoje i edukativne } \\
\text { aplikacije dostupne i na mobilnim uređajima } \\
\text { - } \quad \text { Besplatne aplikacija za antivirusnu zaštitu } \\
\text { - Škole mogu nadomjestit nedostatak IKT } \\
\text { - } \quad \text { Mopreme }\end{array}$ & $\begin{array}{ll}\text { - } & \text { Otežan ili onemogućen pristup internetu } \\
\text { - } & \text { Nedovoljna sigurnost (prijava na mobilnu } \\
\text { mrežu) } & \\
\text { - } & \text { Roditelji možda ne žele kupiti mobilni uređaj } \\
& \text { za korištenje u školi } \\
\text { - } & \text { Stalne promjene iziskuju dodatnu obuku } \\
& \text { učenika i učitelja } \\
\text { - } & \text { Brzo zastarijevanje uređaja } \\
\text { - } & \text { Različite platforme uređaja } \\
\text { - } & \text { Uređaji možda sadržavaju neke zlonamjerno } \\
& \text { napisane programe (malware) } \\
\text { - } & \text { Ograničeni kapacitet memorije, } \\
& \text { kratkotrajnost baterije mobilnih uređaja, } \\
\text { male dimenzije zaslona }\end{array}$ \\
\hline
\end{tabular}

Tablica 2. SWOT analiza uvođenja BYOD modela

\section{Zaključak}

U ovom radu ispitani su stavovi i preferencije učenika osnovnih škola o korištenju mobitela u sklopu nastavnog procesa, te postoji li razlika u percepciji učenika osnovnih i srednjih škola o dopuštenju da donose vlastite uređaje za aktivnosti povezane sa školom.

Rezultati istraživanja pokazuju da velika većina učenika nosi svoj mobilni uređaj u školu stalno ili ponekad. Njih čak $65,69 \%$ smatra da im je nastava zanimljivija kada smiju koristiti svoj mobilni uređaj, a da više učitelja primjenjuje BYOD model, 
odnosno da im dopuste korištenje osobnog mobilnog uređaja za potrebe nastave želi 70,38\% učenika. Obzirom da je detaljnijom analizom podataka utvrđeno da u odgovorima ne postoji razlika obzirom na spol i dob, ovi podaci u potpunosti potvrđuju postavljenu prvu hipotezu.

Prema daljnjim rezultatima vidljivo je da se učenici osnovne škole, u razmišljanjima o dopuštenju da donose vlastite uređaje za aktivnosti povezane sa školom, značajno ne razlikuju od učenika srednjih škola. Kao i učenici srednje škole, smatraju da će najviše utjecaja na njihovo učenje mobiteli imati zbog mogućnosti bržeg pristupanja informacijama za istraživanje (OŠ=72,4\%, SŠ=77,7\%), a jednakog su mišljenja da osobni mobilni uređaj najmanje žele koristiti za komunikaciju s nastavnikom (OŠ $=14,7 \%$, SŠ=28,7\%). No, najveći broj učenika osnovne škole $(62,5 \%)$ izabrao je opciju da bi svoj mobilni uređaj najviše koristili pri istraživanju za projekt, dok bi ga učenici srednje škole ipak koristili najviše za komunikaciju s prijateljima (88,6\%). Učenici osnovne škole smatraju da će donošenje osobnih mobilnih uređaja najmanje utjecati na njihovu angažiranost pri učenju (32,8\%), dok učenici srednje škole najmanji utjecaj vide u mogućnosti slanja radova nastavnicima digitalno (50,3\%). Zbog utvrđivanja ovih manjih razlika postavljena druga hipoteza je samo djelomično potvrđena.

Obzirom na sve navedeno, a kao što $i$ Skupnjak napominje u svom radu (Skupnjak, 2014), škole bi trebale iskoristiti veliki interes učenika za korištenje mobitela te in još više potaknuti da mobitele koriste za učenje, a nastavnike educirati i osvijestiti činjenicu da mobiteli uz pravilno i odgovorno korištenje mogu postati "suradnici u nastavi“ te tako umanjiti njihov negativan stav prema korištenju mobitela u obrazovanju. No, kako za sada ni u osnovnim ni u srednjim školama ne postoji jasno definirano pravilo o donošenju vlastitih uređaja u školi $i$ njegove upotrebi u nastavi, u radu je napravljena SWOT analiza. Na taj način školama bi se olakšala odluka o donošenju pravila o primjeni BYOD modela, a s krajnjim ciljem povećanja aktivnosti učenika na nastavi, poboljšane komunikacije te proširenog mjesta i vremena za učenje (Vanwelsenaers, 2012).

\section{Literatura}

Alberta Education (2012). Bring Your Own Device: A Guide for Schools. Edmonton: Alberta Education. Preuzeto 02. 01. 2019. sa education.alberta.ca/admin/technology.aspx.

Gelenčir M. (2018). Održani pregovori učenika $i$ županije: Poznato hoće li biti prosvjeda zbog ukidanja mobitela u školama. Preuzeto 03. 01. 2019. sa srednja.hr/novosti/hrvatska/odrzanipregovori-ucenika-zupanije-poznato-hoce-libiti-prosvjeda-zbog-ukidanja-mobitelaskolama.

Jazbec J. (2018). Mobiteli u osnovnoj školi - da ili ne?. Zagorje International. Preuzeto 03. 01. 2019. sa www.zagorje-international.hr.

Krmek, M. (2014). Mobilne tehnologije u nastavi. Preuzeto 04.01 .2019$. sa urn.nsk.hr/urn:nbn:hr:147:246288.

Maravić J. (2013). Mobilno učenje. Preuzeto 04. 01. 2019. sa www.skole.hr/obrazovanje-itehnologija?news_id=8951.

Mirković M. (2018). BYOD u obrazovanju. MIPRO. Preuzeto 07. 01. 2019. sa docs.miproproceedings.com/ce/ce_70_4727.pdf.

Skupnjak D. (2014). Mobitel u nastavi: stavovi $i$ iskustva učitelja. Petrijanec. Preuzeto 06. 01. 2019. sa bib.irb.hr/datoteka/705442.Mobitel _u_nastavi_stavovi_i_iskustva_uitelja.pdf.

Stavert B. (2014). Bring Your Own Device (BYOD) in Schools - 2013 Literature Review. NSW Department of Education and Communities. Preuzeto 27. $12.2018 . \quad$ sa education.nsw.gov.au/policy-library/relateddocuments/BYOD_2013_Literature_Review.p df.

Tadić D. (2017). Pametno s pametnim telefonima u učionici. Profil Klett. Preuzeto 02. 01. 2019. sa www.profil-klett.hr/pametno-s-pametnimtelefonima-u-ucionici.

Vanwelsenaers, M. (2012). Students Using Their Own Technology Device in the Classroom: Can 
"Byod" Increase Motivation and Learning. Preuzeto $\quad 30 . \quad 12 . \quad 2018 . \quad$ sa www.nmu.edu/education/sites/DrupalEducati on/files/UserFiles/Vanwelsenaers_Marc_MP.p df.

Wainwright A. (2012). 20 Pros and Cons of implementing BYOD in schools. SecuEdge. Preuzeto $04 . \quad 01 . \quad 2019$ sa www.securedgenetworks.com/blog/20-prosand-cons-of-implementing-byod-in-schools.

\section{Realisation of $m$-learning by using BYOD model in primary school}

\begin{abstract}
Mobile learning or m-learning makes possible the modern ways of learning processes support by using mobile devices. One of the ways of realisation of m-learning is the usage of BYOD model in classroom, towards which teachers mostly show the negative attitude considering that the use of mobile devices in education does not contribute in great deal to the quality of teaching process. The research for the demands of this paper was carried out in March of the school year 2018 /2019 on the sample of 401 students of the subject teaching of 1st and 3rd primary schools Varaždin. The aim was to examine the attitudes and preferences of the primary school students about the use of mobile devices as a part of a teaching process as well as if there is a difference in the perception of primary and secondary school students about the allowance to bring their own devices for the school activities. The results of the research show that even 65,69\% of the students claim that the teaching lessons are more interesting when they are allowed to use their mobile device, and $70,83 \%$ of them want that their teachers use BYOD model in teaching. In addition, the results show that in their opinion to bring their devices for school activities do not differ in great deal from the opinion of the secondary school students.
\end{abstract}

Keywords: mobile phone; BYOD; m-learning; wireless network; students; teachers; teaching. 